\title{
Protective Green Patinas on Copper in Outdoor Constructions
}

\author{
Yolanda Hedberg, Inger Odnevall Wallinder
}

Division of Surface and Corrosion Science, Royal Institute of Technology, KTH, Stockholm, Sweden.

Email: \{yolanda, ingero\}@kth.se

Received June $2^{\text {nd }}, 2011$; revised July 11 ${ }^{\text {th }}$, 2011; accepted August 24 ${ }^{\text {th }}, 2011$.

\begin{abstract}
The last 15 years of research related to atmospheric corrosion and the release of copper to the environment are shortly summarized. Brown and green patinas with high barrier properties for corrosion are gradually evolved on copper at atmospheric conditions. The corrosion process and repeated dry and wet cycles results in a partial dissolution of corrosion products within the patina. Dissolved copper can be released and dispersed into the environment via the action of rainwater, however the major part is rearranged within the patina during drying cycles. The majority of corrosion products formed have a poor solubility, very different from water soluble copper salts. The release process is very slow and takes place independent of patina color. Its extent has only a marginal effect on the adherent patina. Released copper rapidly interacts with organic matter and in contact with different surfaces already in the close vicinity of the building, such as drainage systems, storm water pipes, pavements, stone materials and soil systems. These surfaces all have high capacities to retain copper in the runoff water and to reduce its concentration and chemical form to non-available and non-toxic levels for aquatic organisms.
\end{abstract}

Keywords: Copper, Runoff, Patina

Copper surfaces on external buildings such as roofs of ancient churches, and claddings of historic structures, for instance the Statue of Liberty in New York, US, have with time developed a green to turquoise color, Figure 1 (left). Green patinas are rapidly evolved with time in highly polluted environments and their components, which determine their color, depend on prevailing environmental conditions and on concentrations of air pollutants, aerosols and particulates, such as sulfur dioxide and sodium chloride. In low-polluted environments, the metallic lustre of copper is often maintained, or gradually changed with time to a brown-black shade. The greenish appearance will hardly ever occur at these conditions, or evolve extremely slowly. As gaseous concentrations of sulfur dioxide have decreased substantially during the last decades in Europe and the US, black-brown patinas are nowadays predominantly developed in favor of green patinas. This is unfortunately not the case for rapidly developing countries in Asia and Africa, due to the high degree of pollutants.

Why is a patina developed on copper metal and why is its color typically brown and/or green? All metals, with the exception of very noble metals such as gold and platinum, are oxidized and corroded to different extent when exposed to ambient outdoor conditions. Well-known examples where these processes are clearly visible and evident are red-rust formation on iron or steel constructions, and white rust staining on galvanized steel surfaces. However, the oxidation of metals or alloys such as titanium and stainless steel is not possible to observe by the naked eye at identical exposure conditions. These surfaces hence often maintain their metallic appearance also after several decades of exposure. For copper however, outdoor exposures result in the gradual evolution of corrosion products that exhibit different colors. The initially formed copper oxide (cuprite) is responsible for a gradually progressively more brown-black surface appearance, whereas different basic copper sulfates and chlorides make the surface greenish, Figure 1 (left).

The evolution of corrosion products within the patina depends on prevailing environmental conditions, in particular concentrations of sulfur dioxide and sodium chloride. In marine environments, deposition of chlorides in sea-salt aerosols results in the formation of basic copper chlorides turning the copper surface green-turquoise. Even though the outer patina layer is greenish in color, 

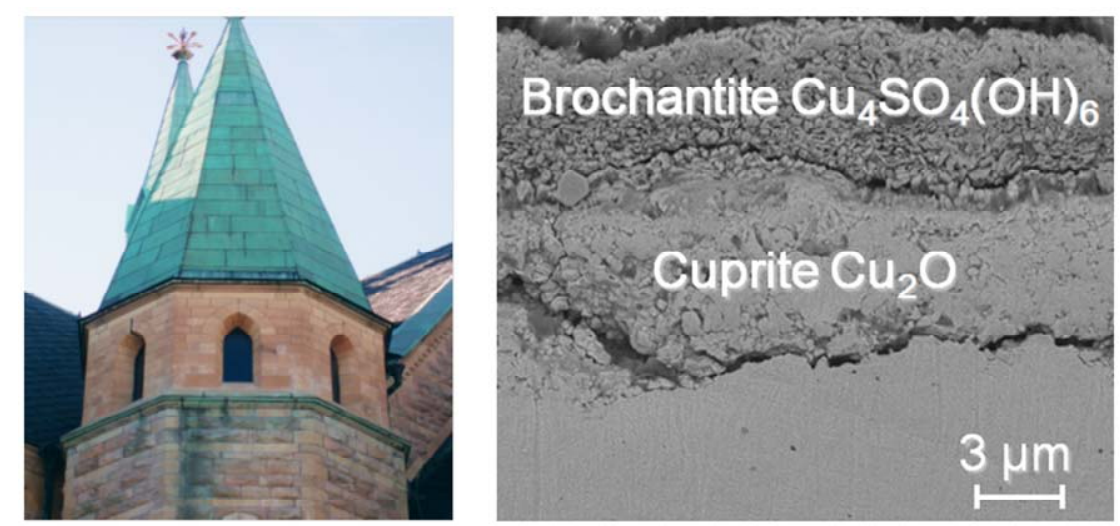

Figure 1. Green patina on a copper roof of a church in Stockholm, and released copper retained by the stone plinth beneath the roof (left). A cross section of a 350 year old naturally aged corroded copper roof with an outer green patina layer of basic copper sulfates and an inner brown layer of copper oxide (right).

the inner layer is predominantly black-brownish and composed of cuprite, Figure 1 (right). This is also true for green patina evolved in polluted (e.g. sulfur dioxide) environments where typically different basic copper sulfates (and other phases) form the green outer patina layer. In non-marine and low polluted environments, or when the copper metal is freshly exposed, the patina turns brownish in color. This is related to the fact that no, or low amounts of predominantly basic copper compounds are formed and integrated with the brown-black patina.

The gradually developed patina, independent of color and composition, is strongly adherent to the surface and acts as an efficient barrier that significantly reduces the corrosion rate of the underlying copper metal. Also the diffuse dispersion of copper from outdoor constructions is relatively independent of patina composition and color. This partial dissolution of copper from corrosion products within the patina that may be dispersed into the environment via the action of rainwater is however a very slow process and of marginal importance for the adherent patina. Patinas aged during centuries possess hence still high barrier properties due to its patina constituents and most of the underlying copper metal is still non-oxidized, a scenario that would not occur in the presence of of easily soluble corrosion products such as copper salts.

You may believe that a green patina, which is partially composed of basic copper sulfates and/or basic copper chlorides, dissolves as rapidly as a water soluble salt of copper sulfate or copper chloride. This assumption is highly erroneous for several reasons. Firstly, basic copper compounds evolved in copper patinas are chemically very different compared to soluble copper salts, secondly, the basic copper compounds are integrated within the patina, predominantly composed of cuprite, and thirdly, the thin water film conditions combined with repeated dry and wet periods that govern atmospheric exposure conditions enable partially dissolved copper released from patina constituents to re-precipitate during drying cycles. These conditions are very different from bulk immersion conditions where no dry period occurs and dissolved copper has limited possibility to re-precipitate. It is only via the action of rain water flushing the surfaces that any dissolved copper can be released from the copper surface into the environment. The action of rainwater essentially depends on rain characteristics and prevailing wind directions and to factors such as building geometry, orientations and inclinations of roofs and facades, rain sheltered surfaces etc. As an example, only a very small surface area of a facade orientated opposite the prevailing wind direction or being partly rain sheltered by nearby buildings will be exposed to rainfall, whereas the entire surface of a copper roof will be exposed to rain able to transport dissolved copper from the patina.

How will released copper interact with the environment and does this dispersion pose any potential risks or hazards? Extensive research efforts have been conducted to understand the metal release mechanisms and the environmental interaction and fate of released copper from outdoor constructions, Figure 2. Most ecotoxicological studies are conducted on easily water soluble salts to assess adverse effects on aquatic organisms induced by metals in their ionic form. Such experiments can however not directly be used to assess the behavior of released copper from brown or green copper patina due to the following reasons. Any release of copper requires, as previously discussed, the action of rainwater to transport dissolved copper from the surface. Its extent depends on prevailing meteorological and environmental conditions including factors such as rain characteristics (intensity, amount, duration, acidity), duration of wet and dry periods preceding rain events, pollutant levels as well as surface orientation and inclination. Released copper will 


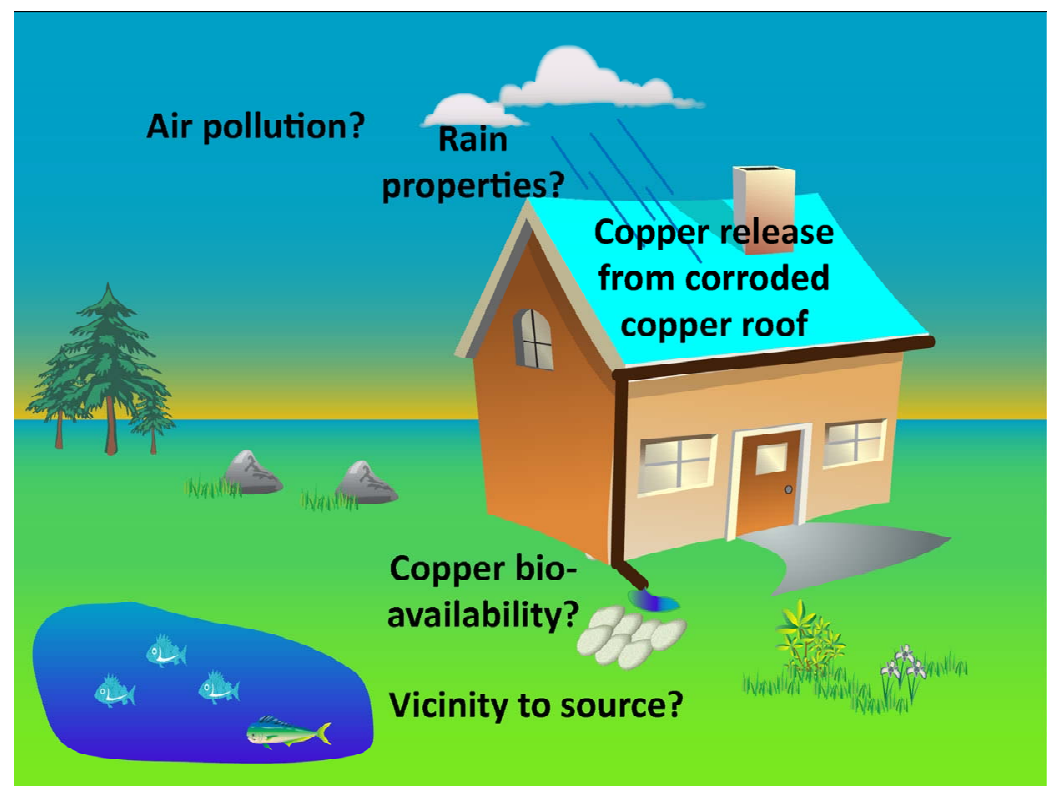

Figure 2. Green and brown patinas formed on copper roofs and facades efficiently reduces the corrosion rate of copper and acts as protective barriers for the underlying copper metal. Via the action of impinging rainwater, a small amount of copper, partly dissolved from corrosion products in the patina during repeated dry and wet cycles, can be released to the environment. Its chemical form and environmental fate depend on interactions with organic matter and different solid surfaces from source to recipient. Most copper has been shown to be retained in the close vicinity to its source and doesn't induce any adverse effects on aquatic organisms.

rapidly interact with for instance organic matter forming non-available complexes and/or be retained by surfaces and materials already in the drainage system dewatering for instance a copper roof. Surfaces in drain pipes and urban storm water systems, such as concrete and cast iron, have proven to be efficient sinks for released copper. They also efficiently change the chemical form of copper to non-available complexes, a condition very different from ecotoxicological testing with copper salts where all copper is in a bioavailable chemical form. Actually, more than $98 \%$ of the total amount of released copper in runoff water is retained by concrete surfaces forming different stable copper compounds already after $20 \mathrm{~m}$ of interaction. These interactions are visible by the naked eye as greenish areas on for instance pavements were runoff water from a copper roof is directed and flushed before entering the storm water system, and on concrete or limestone plinths beneath ancient bronze statues or copper roofs, Figure 1 (left). These surfaces as well as soil systems and sediments act as very efficient sinks for copper released from brown and green patinas on copper in outdoor constructions. They also have a capacity to change the chemical speciation of the low fraction of non-retained copper to copper complexes that are non-available to sensitive aquatic organisms. Copper released from green and brown patinas due to the combined action of corrosion and rainwater has clearly been proven to induce negligible adverse environmental effects due to its rapid and strong interaction with different solid surfaces and organic matter upon transport from source to recipient. Also, to compare the potential impact of copper levels from roof run-off, the dilution of the roof run-off into the receiving surface water needs to be considered. However, if copper-containing runoff water from a large roof is directly directed into a small volume of receiving water (e.g. a small pond) without any possibility for natural pre-interactions with organic matter and/or different surfaces, or dilution, precautionary actions should be undertaken.

In all, brown and green patinas with high barrier properties for corrosion are gradually evolved on copper at atmospheric conditions. The corrosion process and repeated dry and wet cycles results in a partial dissolution of corrosion products within the patina. Dissolved copper can be released and dispersed into the environment via the action of rainwater, however the major part is rearranged within the patina during drying cycles. The majority of corrosion products formed have a poor solubility, very different from water soluble copper salts. The release process is very slow and takes place independent of patina color. Its extent has only a marginal effect on the adherent patina. Released copper rapidly interacts with organic matter and in contact with different surfaces already in the close vicinity of the building, such as drain- 
age systems, storm water pipes, pavements, stone materials and soil systems. These surfaces all have high capacities to retain copper in the runoff water and to reduce its concentration and chemical form to non-available and non-toxic levels for aquatic organisms. This chemical form is very different from copper dissolved from water soluble copper salts used in ecotoxicological investigations. Countermeasures may be undertaken if rainwater from a copper roof is directed into a lake without any possibility for interactions with organic matter or solid surfaces adjacent the building.

\section{REFERENCES}

[1] I. Odnevall Wallinder, Y. Hedberg and P. Dromberg, "Storm Water Runoff Measurements of Copper from a Naturally Patinated Roof and from a Parking Space. Aspects on Environmental Fate And Chemical Speciation,” Water Research, Vol. 43, No. 20, 2009, pp. 5031-5038. doi:10.1016/j.watres.2009.08.025

[2] B. Bahar, G. Herting, I. Odnevall Wallinder, K. Hakkila, C. Leygraf and B. Virta, "The Interaction between Concrete Pavement and Corrosion-Induced Copper Runoff from Buildings," Environmental Monitoring and Assessment, Vol. 140, No. 1-3, 2008, pp. 175-189. doi:10.1007/s10661-007-9858-0
[3] I. Odnevall Wallinder, B. Bahar, C. Leygraf and J. Tidblad, "Modelling and Mapping of Copper Runoff for Europe,” Journal of Environmental Monitoring, Vol. 9, 2007, pp. 66-73. doi:10.1039/b612041e

[4] S. Bertling, I. Odnevall Wallinder, D. Berggren and C. Leygraf, "Long Term Corrosion-Induced Copper Runoff from Natural and Artificial Patina and Its Environmental Fate,” Environmental Toxicology and Chemistry, Vol. 25, No. 3, 2006, pp. 891-898. doi:10.1897/05-027R.1

[5] S. Bertling, F. Degryse, I. Odnevall Wallinder, E. Smolders and C. Leygraf, "Model Studies of Corrosion-Induced Copper Runoff Fate in Soil,” Environmental Toxicology and Chemistry, Vol. 25, No. 3, 2006, pp. 683-691.

[6] A. Krätschmer, I. Odnevall Wallinder and C. Leygraf, "The Evolution of Outdoor Copper Patina," Corrosion Science, Vol. 44, No. 3, 2002, pp. 425-450.

[7] C. Karlén, I. Odnevall Wallinder, D. Heijerick and C. Leygraf, "Runoff Rates, Chemical Speciation and Bioavailability of Copper Dispersion from Naturally Patinated Copper Roofs,” Environmental Pollution, Vol. 120, No. 3, 2002, pp. 691-700.

[8] W. He, I. Odnevall Wallinder and C. Leygraf, “A Comparison between Corrosion Rates and Runoff Rates from New and Aged Copper and Zinc as Roofing Materials," Water, Air and Soil pollution: Focus, Vol. 1, 2001, pp. 67-82. 